\title{
Increasing Prevalence of Assisted Living as a Substitute for Private-Pay Long-Term Nursing Care
}

\author{
Benjamin C. Silver (D, David C. Grabowski, Pedro L. Gozalo, \\ David Dosa, and Kali S. Thomas
}

Objective. Given the tremendous growth in assisted living (AL) over the past 20 years, it is important to understand how expansion has affected the demand for long-term care (LTC) provided in nursing homes (NHs). We estimated the effect of a change in county-level AL beds on the prevalence of private-pay residents and privatepay resident days at the $\mathrm{NH}-$ level.

Data Sources. National census of large AL providers (25+ beds), and Minimum Data Set combined with Medicare enrollment records and claims from 2007 and 2014.

Study Design. Retrospective longitudinal analysis of LTC markets.

Principal Findings. Mean AL beds per county increased from 285 to 324, while NHs exhibited a decrease in private-pay residents (20.1 to 17.7 percent) and resident days (21.3 to 17.5 percent). An increase of $1,000 \mathrm{AL}$ beds at the county level is associated with a reduction of 0.44 percentage points in privatepay resident days but is not significantly associated with percent of private-pay residents.

Conclusions. These results suggest that increases in AL capacity have potentially allowed NH residents to delay or decrease their privately financed lengths of stay. As demand for AL continues to grow, it will be important to assess the effects on other LTC sectors.

Key Words. Assisted living, nursing home, long-term care

The assisted living (AL) sector has experienced tremendous expansion over the past 20 years as a form of long-term care (LTC) for older and disabled Americans. Although the services offered can vary considerably across communities, AL has been defined as "a congregate residential setting that provides or coordinates personal services, 24-hour supervision and assistance (scheduled and unscheduled), activities, and health-related services" (Assisted Living Quality Coalition 1998; Hawes et al. 2003; 
Phillips et al. 2005). The AARP Public Policy Institute reports that the number of licensed AL beds in the U.S. increased from an estimated $1,224,982$ in 2010 to $1,304,347$ in 2013. The prevalence of AL beds varies considerably across geographic locations, ranging at the state level from $11(\mathrm{NV})$ to 125 beds $(\mathrm{MN})$ per 1,000 residents aged 65+ in 2013 (AARP Public Policy Institute (2017). Given this increase and geographic variability, it is important to understand the effect this expansion has had on the demand for other types of LTC, specifically that provided in nursing homes (NHs).

In this paper, we examine the association of the growth of AL in recent years and concurrent changes in $\mathrm{NH}$ utilization. Thus far, research in this area has been limited primarily due to data limitations. One study found that an increase in AL capacity in 13 states between 1993 and 2007 was associated with a decline in private-pay $\mathrm{NH}$ occupancy (Grabowski, Stevenson, and Cornell 2012). However, this initial study was limited in scope (only measuring changes in 13 states because of the availability of longitudinal AL data) and in its definition of private-pay $\mathrm{NH}$ occupancy (utilizing a point-in-time measure of the count of private-pay residents only available annually per $\mathrm{NH}$ ). A second study examined the state of Ohio from 1993 to 2007 and found that expansion of AL within a market increases concentration of the $\mathrm{NH}$ market, but does not affect NH pricing (Bowblis 2014). These initial findings suggest that AL capacity has a modest but significant impact on who uses $\mathrm{NH}$ care and how it is financed.

Building on this research, we will improve our ability to identify the effect of the changing AL bed supply in various markets, nationally, on the market for $\mathrm{NH}$ care with an innovative measure that uses resident-level data to capture the number of private-pay $\mathrm{NH}$ days. A better understanding of the effect of the AL market on other sectors of LTC, namely $\mathrm{NH}$ private-pay occupancy and length of stay, is expected to result.

Address correspondence to Kali S. Thomas, Ph.D., M.A., Health Services, Policy and Practice, Brown University School of Public Health, Box G-S121(6), Providence, RI 02912; and also Department of Veterans Affairs Medical Center, Providence, RI. e-mail: Kali_Thomas@brown.edu. Benjamin C. Silver, Ph.D., Pedro L. Gozalo, Ph.D., M.Sc., and David Dosa, M.D., M.P.H., are with the Brown University School of Public Health, Providence, RI. David C. Grabowski, Ph.D., is with the Department of Health Care Policy, Harvard Medical School, Boston, MA. Benjamin C. Silver, Ph.D., is also with Health Care Financing and Payment, RTI International, Waltham, MA. David Dosa, M.D., M.P.H., is with the Department of Veterans Affairs Medical Center, Providence, RI.

[Correction added on 20 August 2018, after first online publication: the corresponding author of this article has been changed to "Kali S. Thomas".] 


\section{Conceptual Framework}

Our conceptual framework was derived from past work by Grabowski and colleagues and the standard economic model of LTC utilization (Pezzin, Kemper, and Reschovsky 1996; Grabowski, Stevenson, and Cornell 2012). This model describes utilization of a particular type of LTC as a function of the cost of the care and an individual's means, preferences, and medical needs or functional impairments. Prior to the introduction of AL, the decision faced by an individual needing LTC was whether to obtain those services at home or in a formal $\mathrm{NH}$ setting. Because medical and functional needs generally increase over time and until death, we expect that on average, older, more impaired individuals would be more likely to demand the more comprehensive NH setting. However, $\mathrm{NH}$ residence is often less desirable to those needing LTC because it is more limiting when compared with the comfort and independence of one's home (Goda, Golberstein, and Grabowski 2011). NH residence is also quite costly when paid for out-of-pocket, though Medicaid covers residence in a $\mathrm{NH}$ for the majority of low-income individuals and those who have spent down their assets (Kaye, Harrington, and LaPlante 2010; Grabowski, Stevenson, and Cornell 2012; Wiener et al. 2013). This overall reduction in utility associated with $\mathrm{NH}$ residence may lead individuals to delay transitioning to a $\mathrm{NH}$ beyond a point that strikes an ideal balance of comfort, cost, and health.

The introduction of AL into the market for LTC may offer many individuals a desirable new alternative. From a cost perspective, AL offers a lower cost form of residential LTC when compared with $\mathrm{NH}$ residence for those individuals paying out-of-pocket for their care. Although costs are generally higher than continuing to live at home, a number of services and supports become available without a substantial reduction in comfort or independence. This combination can allow many individuals to postpone transitioning to a $\mathrm{NH}$ for a longer period while receiving an increasing level of LTC services. In addition, it can provide an alternative setting for residents discharged from NHs. Thus, we expect that individuals whose medical and financial circumstances allow would elect to reside in an AL community instead of a $\mathrm{NH}$.

We envision two specific scenarios where this may occur. First, community-dwelling individuals who experience an acute event followed by postacute care and are no longer able to return to living in the community may transition to AL after completing rehabilitation. Second, AL may serve as a bridge between community residence and NH-based LTC as function begins to decline. In both cases, we expect that the effect will be concentrated on individuals whose LTC is privately financed (i.e., not covered by Medicaid), as the 
majority of AL residents are required to pay out-of-pocket for their housing and services (Phillips et al. 2005; Harris-Kojetin et al. 2016; Khatutsky et al. 2016). Building on this framework, we hypothesized that as the capacity for $\mathrm{AL}$ increased in a market (county), the rates of private-pay residents in $\mathrm{NHs}$ and their lengths of stay would have decreased.

\section{METHODS}

\section{Assisted Living and Market Data}

Data on AL providers including their addresses, licensure type, and size (i.e., number of beds) came from a national list of licensed residential care facilities (i.e., facilities that are licensed, registered, listed, certified, or otherwise regulated by the states) compiled by the authors from individual state licensing agencies in 2007 and again in 2014. States include a wide range of licensure categories for congregate residential facilities (e.g., residential care facilities, assisted living facilities, community living arrangements, adult family care homes, and personal care homes). Therefore, following past work, we defined "assisted living" as a community with $25+$ beds and licensed to serve an elderly population (Stevenson and Grabowski 2010; Grabowski, Stevenson, and Cornell 2012; Thomas et al. 2018). In 2012, these constituted approximately 41.4 percent of all AL communities in the United States, and 82.2 percent of AL beds (Harris-Kojetin et al. 2013). Two states, Indiana and Tennessee, were excluded due to inconsistent AL data between the years that we were unable to reconcile. Consistent with our previous work examining the market for LTC, we used county boundaries to define each market (Banaszak-Holl, Zinn, and Mor 1996; Grabowski and Hirth 2003; Grabowski 2008; Stevenson and Grabowski 2010; Grabowski, Stevenson, and Cornell 2012; Thomas et al. 2013). Market-level characteristics were drawn from publicly available data from the U.S. Census Bureau.

\section{Nursing Home Data}

Data on NH utilization came from the Residential History File (RHF), which is comprised of information from the Minimum Data Set, the Medicare Master Beneficiary Summary File (MBSF), and Medicare claims (Intrator et al. 2011). Additional NH data were also incorporated from Long-Term Care: Facts on Care in the U.S. (LTCfocUS.org), which is derived, in part, from the 
Online Survey Certification and Reporting (OSCAR) database and the Minimum Data Set (Brown University School of Public Health 2011).

\section{Sample Characteristics and Variables of Interest}

We included 14,993 NHs operating in 2007 and 14,569 NHs operating in 2014. These facilities were located in 2,735 and 2,744 counties, respectively. Our outcome variables of interest were the percent of residents in the $\mathrm{NH}$ who were private-pay during each calendar year (2007 and 2014), and the percent of resident days in each $\mathrm{NH}$ in the calendar year that were privately financed. We estimated NH-level private-pay utilization with our RHF methodology as described and validated by Thomas and colleagues (Thomas et al. 2017). This methodology identifies the percent of total $\mathrm{NH}$ days for Medicare beneficiaries in each facility that were privately paid using the following logic: Private-pay NH days were NH days that are neither covered by the Medicare Skilled Nursing Facility benefit (as identified by Medicare inpatient claims dates) nor a time period when a resident was dually eligible for Medicare and Medicaid (as indicated by the monthly flag in the Medicare Master Summary Beneficiary file). For Medicare Advantage beneficiaries, after day 100 of a consecutive NH stay, we assumed that the SNF benefit had ended for these residents. If they were not dually eligible, then we assumed that they converted to private-pay. We aggregated these values to the $\mathrm{NH}$ level and constructed a private-pay resident prevalence rate on the first Thursday in April in 2007 and 2014. We also calculated the percent of resident days in the $\mathrm{NH}$ during the calendar year that were privately financed.

Our primary independent variable was the number of AL beds in the county (market). We controlled for NH fixed effects and several time-varying market-level characteristics including: median household income (inflation adjusted to 2014 dollars), the percent of residents who were white, the number of residents aged 65 or over, the number of $\mathrm{NH}$ beds in the county, and the percent of Medicare beneficiaries in the county who are dually eligible for Medicare \& Medicaid.

\section{Analyses}

We estimated the effect of a change in market/county-level AL capacity (beds) on private-pay $\mathrm{NH}$ utilization at the $\mathrm{NH}$-level using ordinary least squares regression with two-way ( $\mathrm{NH}$ and year) fixed effects. We conducted two analyses, one estimating the effect of AL capacity on the percent of private-pay 
residents in the $\mathrm{NH}$, and one estimating the effect on the percent of privately paid resident days. To do this, we specified the following model:

$$
\mathrm{PPV}_{i c t}=\alpha_{i c t}+\gamma_{t}+\delta_{i}+\beta \mathrm{ALF}_{i c t}+v z_{c t}^{\prime}+\varepsilon_{i c t}
$$

where $i$ represented a NH in county $c$ at time $t$ (month/year). Therefore, $\gamma_{t}$ represented the year fixed effect, $\delta_{i}$ represented the county fixed effect, and $\beta \mathrm{ALF}_{i c t}$ represented the within county effect of a change in county-level AL capacity (beds) on the NH-level rate of private-pay utilization. The $\alpha_{i c t}$ represented the constant, and $\varepsilon_{i c t}$ was the error term. The $v_{c t}^{\prime}$ in our model represented our market-level control variables. The two-way fixed effects model controls for all time-invariant $\mathrm{NH}$-level and market-level characteristics. We also clustered standard errors at the county level. Coefficients in this model should be interpreted as the change in the outcome in percentage points associated with a one unit increase in the covariate.

\section{Sensitivity Analyses}

To test the robustness of our findings, we conducted a falsification test in which we estimated NH-level Medicare-financed utilization (i.e., under the benefit for postacute, rehabilitative skilled nursing facility care), including the prevalence rate and the percent of resident-days as dependent variables private-pay. Following the example of past work (Grabowski, Stevenson, and Cornell 2012), we hypothesized that care covered by the Medicare postacute care SNF benefit would not be affected by changes in the AL market because AL is not a substitute for postacute care, and any relationships observed could be evidence of endogeneity in our measure of AL supply. All analyses were conducted using the "areg" function of Stata 15.

\section{RESULTS}

\section{Descriptive Analyses}

Descriptive characteristics of NHs and markets are shown in Table 1. AL capacity varied widely across counties; but, we observed an overall increase in the mean capacity from 285 (standard deviation =954) to 324 (standard deviation $=937$ ) beds. Among NHs, the average percent of private-pay residents and private-pay resident days decreased significantly $(p<.001)$ : the percent of private-pay residents decreased from 20.1 percent in 2007 to 17.7 percent in 2014 , and the percent of resident days that were private-pay decreased from 
Table 1: Long-Term Care Utilization and Market Characteristics (2007 and 2014)

\begin{tabular}{|c|c|c|c|}
\hline & 2007 & 2014 & $p$-Value \\
\hline \multicolumn{4}{|l|}{ Nursing home characteristics } \\
\hline Total NH residents $^{\dagger}(N)$ & $1,207,674$ & $1,086,184$ & - \\
\hline Total private-pay NH residents ${ }^{\dagger}(N)$ & 213,809 & 165,050 & - \\
\hline \multicolumn{4}{|l|}{ Nursing home private-pay utilization } \\
\hline$N$ Private-pay residents ${ }^{\dagger}-$ mean $(\mathrm{SD})$ & $14.3(13.3)$ & $11.3(13.0)$ & $<.001$ \\
\hline$\%$ Private-pay residents ${ }^{\dagger}-$ mean $(\mathrm{SD})$ & $20.1(15.8)$ & $17.7(17.0)$ & $<.001$ \\
\hline $\begin{array}{l}N \text { Private-pay resident } \\
\text { days - mean }(\mathrm{SD})\end{array}$ & $5,515.27(5,048.60)$ & $4,064.98(4,420.21)$ & $<.001$ \\
\hline $\begin{array}{l}\text { \% Private-pay resident } \\
\text { days - mean }(\mathrm{SD})\end{array}$ & $21.3(15.9)$ & $17.5(16.1)$ & $<.001$ \\
\hline \multicolumn{4}{|l|}{ Market characteristics } \\
\hline Total AL beds—-mean (SD) & $285(954)$ & $324(937)$ & .126 \\
\hline $\begin{array}{l}\text { Median household income } \\
\text { (in thousands)—mean (SD) }\end{array}$ & $49.5(12.6)$ & $47.2(12.1)$ & .000 \\
\hline$\%$ Population white - mean $(\mathrm{SD})$ & $86.2(15.7)$ & $84.8(15.8)$ & .002 \\
\hline $\begin{array}{l}\text { Total residents aged } 65 \\
\text { and over-mean }(\mathrm{SD})\end{array}$ & $13,136(36,549)$ & $16,141(44,621)$ & .006 \\
\hline Total NH beds-mean $(\mathrm{SD})$ & $582(1,524)$ & $572(1,481)$ & .819 \\
\hline $\begin{array}{l}\% \text { population dually } \\
\text { eligible-mean }(\mathrm{SD})\end{array}$ & $16.2(8.4)$ & $14.0(7.1)$ & .000 \\
\hline
\end{tabular}

Notes. Number of nursing homes in our sample $=14,993$ (2007) and 14,569 (2014); number of markets/counties in our sample $=2,735,2,744$. Mean Nursing Home Characteristics is the average across nursing homes. Mean Market Characteristics is the average across counties.

${ }^{*} p$-Values determined by two-tailed $t$-test.

tPrevalence estimate on the first Thursday in April of the corresponding year.

${ }^{\ddagger}$ Median household income inflation adjusted to 2014 dollars.

$\mathrm{AL}$, assisted living; $\mathrm{NH}$, nursing home; $N$, number; $\mathrm{SD}$, standard deviation.

21.3 to 17.5 percent over this time period. At the market level, inflationadjusted median household income significantly decreased from $\$ 49.5$ thousand to $\$ 47.2$ thousand $(p<.001)$ over this time period. The percent of the county's Medicare beneficiaries dually eligible for Medicare and Medicaid significantly decreased from 16.2 to 14.0 percent $(p<.001)$. The total population aged 65 years and older increased during this period $(p=.006)$. The mean total $\mathrm{NH}$ beds decreased slightly, but this change was not statistically significant.

\section{Main Models}

Results from our multivariate analyses suggest that change in AL capacity was associated with a modest reduction in the proportion of private-pay residents 
that was not statistically significant. However, our results examining the relationship between AL capacity and private-pay $\mathrm{NH}$ days suggest that an increase of 1,000 AL beds at the county-level is associated with a reduction of 0.44 percentage points in private-pay resident days $(95 \% \mathrm{CI}=-0.71$ to -0.17$)$ (See Table 2). This translates to approximately 1,932,063 NH person-days over this time period, or 276,009 per year, nationally. Importantly, although we observe an overall significant increase in AL capacity nationally, the level of increase varied widely across markets.

Over time, there was an independent decrease of 1.9 percentage points $(95 \% \mathrm{CI}=-2.4$ to -1.3$)$ in private-pay residents, and a 2.9 percentage point decrease $(95 \% \mathrm{CI}=-3.4$ to -2.5$)$ in private-pay resident days. Higher median household income was associated with greater private-pay $\mathrm{NH}$ residents $(0.2$ percentage points, $95 \% \mathrm{CI}=0.1$ to 0.3 ) and private-pay $\mathrm{NH}$ days ( 0.2 percentage points, $95 \% \mathrm{CI}=0.1$ to 0.3$)$. County percentage of white residents was not associated with percent of private-pay $\mathrm{NH}$ residents or resident days. County percentage of residents who were dually eligible for Medicare and Medicaid was significantly associated with both private-pay residents $(-0.1$ percentage points, $95 \% \mathrm{CI}=-0.2$ to -0.1$)$ and resident days $(-0.2$ percentage points, $95 \% \mathrm{CI}=-0.2$ to -0.1 ). Total residents over age 65 years (in thousands) exhibited a small but significant association with both outcome measures, and total NH beds (in hundreds) was associated with private-pay resident days $(0.1$ percentage points, $95 \%$ CI 0.0 to 0.1 ).

Table 2: Results from Two-Way Fixed Effects Models Examining the Association between Change in County-Level Assisted Living Capacity and Private-Pay Nursing Home Utilization

\begin{tabular}{|c|c|c|}
\hline Outcome Variable & $\%$ Private-Pay Residents & $\%$ Private-Pay Resident Days \\
\hline AL beds (in thousands) & $-0.19(-0.50$ to 0.11$)$ & $-0.44 * * *(-0.71$ to -0.17$)$ \\
\hline Year 2014 (ref. 2007) & $-1.85^{* * *}(-2.36$ to -1.35$)$ & $-2.94 * * *(-3.39$ to -2.50$)$ \\
\hline $\begin{array}{l}\text { Median household income } \\
\text { (in thousands) }\end{array}$ & $0.17 * * *(0.09$ to 0.25$)$ & $0.18 * * *(0.11$ to 0.25$)$ \\
\hline Percent white & $0.06(-0.13$ to 0.26$)$ & $0.16(-0.02$ to 0.34$)$ \\
\hline $\begin{array}{l}\text { Total residents age } 65 \text { and } \\
\text { over (in thousands) }\end{array}$ & $-0.01 * *(-0.02$ to 0.00$)$ & $-0.02 * * *(-0.03$ to -0.01$)$ \\
\hline Total NH beds (in hundreds) & $0.04(-0.01$ to 0.08$)$ & $0.06^{* * *}(0.02$ to 0.09$)$ \\
\hline Percent dual & $-0.12^{* * *}(-0.19$ to -0.05$)$ & $-0.15^{* * *}(-0.21$ to -0.09$)$ \\
\hline
\end{tabular}

Notes. Covariates measured at the county level. Values represent effect estimate in whole percentage points (95\% confidence interval). Two-way fixed effects models control for nursing home and year.

$* p<.05, * * p<.01, * * * p<.001$.

AL, assisted living; $\mathrm{NH}$, nursing home. 
Table 3: Results from Two-Way Fixed Effects Models Examining the Association between Change in County-Level Assisted Living Capacity and Medicare-Financed Nursing Home Utilization

\begin{tabular}{|c|c|c|}
\hline Outcome Variable & $\%$ Medicare Residents & \% Medicare Resident Days \\
\hline AL beds (in thousands) & $-0.07(-0.43$ to 0.29$)$ & $-0.01(-0.28$ to 0.25$)$ \\
\hline Year 2014 (ref. 2007) & $0.53 *(0.07$ to 0.98$)$ & $1.12 * * *(0.75$ to 1.49$)$ \\
\hline $\begin{array}{l}\text { Median household income } \\
\text { (in thousands) }\end{array}$ & $-0.11^{* * *}(-0.17$ to -0.04$)$ & $-0.11 * * *(-0.16$ to -0.05$)$ \\
\hline Percent white & $0.11(-0.13$ to 0.35$)$ & $-0.02(-0.23$ to 0.19$)$ \\
\hline $\begin{array}{l}\text { Total residents aged } 65 \\
\text { and over (in thousands) }\end{array}$ & $-0.01(-0.02$ to 0.00$)$ & $0.00(-0.01$ to 0.00$)$ \\
\hline Total NH beds (in hundreds) & $0.06 *(0.00$ to 0.12$)$ & $0.02(-0.02$ to 0.06$)$ \\
\hline Percent dual & $-0.13^{* * *}(-0.19$ to -0.07$)$ & $-0.13 * * *(-0.17$ to -0.08$)$ \\
\hline
\end{tabular}

Notes. Covariates measured at the county level. Values represent effect estimate in whole percentage points (95\% confidence interval). Two-way fixed effects models control for nursing home and year.

$* p<.05, * * p<.01, * * * p<.001$.

AL, assisted living; $\mathrm{NH}$, nursing home.

\section{Sensitivity Analyses}

The results of our falsification test suggested that AL capacity was not significantly associated with either measure of Medicare-financed $\mathrm{NH}$ utilization (see Table 3). Although the share of Medicare-financed residents ( 0.5 percentage points, $95 \% \mathrm{CI}=0.1$ to 1.0 ) and resident days (1.1 percentage points, $95 \%$ $\mathrm{CI}=0.8$ to 1.5$)$ increased nationally over our study period, time-varying county characteristics exhibited few significant relationships with our outcome measures.

\section{DISCUSSION}

Understanding the effect of the AL supply on alternative LTC options, such as NHs, will inform how to better prepare the LTC market for the expected increases in demand for LTC over the next 25 years (Hagen 2013). While we did not observe a statistically significant association between increases in AL capacity and the percent of private-pay $\mathrm{NH}$ residents, we did observe a decrease in the percent of privately financed $\mathrm{NH}$ days of care. This suggests that although the percent of private-pay residents in NHs may not have changed as AL capacity increased, there was a reduction in the amount of time that these residents paid privately for their $\mathrm{NH}$ care. Specifically, we found that a 
county-level increase of 1,000 AL beds from 2007 to 2014 resulted in a decrease of 0.44 percentage points in privately financed $\mathrm{NH}$ resident days within that county, translating to $1,932,063 \mathrm{NH}$ person-days nationally, or 276,009 per year.

Our finding that the percent of private-pay residents in NHs was not affected by the change in AL capacity contrasts past work that found a 10 percent increase in market-level AL capacity corresponded to a 1.4 percent reduction in NH private-pay occupancy at the mean (Grabowski, Stevenson, and Cornell 2012). Several factors may have contributed to this difference in results: first, we utilized a national sample for this work whereas the previous study only examined changes within thirteen states. Second, we examined changes over a different period of time (2007-2014 vs. 1993-2007) and used a different data source for our measure of private-pay NH utilization. However, our robustness check agreed with past work finding that there was no association between market-level AL supply and Medicare-financed NH utilization, suggesting that the $\mathrm{AL}$ expansion that we observed is not endogenous with changing market demands.

We hypothesize several possible drivers of our finding that increases in AL capacity reduces the percent of privately financed $\mathrm{NH}$ days. Our results suggest that AL could be allowing individuals to reside in these settings as their function begins to decline, thereby postponing (or possibly eliminating, depending on the level of functional decline prior to death) their use of $\mathrm{NH}$ care. It is also possible that individuals recovering from an acute event who are no longer able to live at home at the completion of their postacute rehabilitation are transitioning to $\mathrm{AL}$ instead of remaining in the $\mathrm{NH}$. In addition to examining the influence of increasing AL supply on individuals' LTC trajectories, future research is needed to understand additional mechanisms behind the decline witnessed in private-pay NH days that were not accounted for in this study (e.g., changes in health and functioning, availability of additional long-term services and supports, expanded informal supports).

When interpreting our findings, it is important to note that although individuals may choose $\mathrm{AL}$ rather than a $\mathrm{NH}, \mathrm{AL}$ is not a care delivery substitute for NH. Unlike NHs, ALs are neither federally regulated nor federally funded, thereby precluding any standardization in staffing, quality, and the types of services that must be provided to residents. Therefore, ALs vary substantially in their cost, amenities, and ability to care for residents with complex medical conditions or severe functional limitations. Future research is needed to better understand the role of AL expansion in diverting or decreasing the length of private-pay $\mathrm{NH}$ stays as well as the potential impact receiving LTC 
in an AL can have on individuals who might have previously utilized privately financed $\mathrm{NH}$ care.

Our results have important implications for the future of the LTC market. As demand for LTC shifts from NHs to the less expensive, less restrictive, and often more preferred form of LTC provided in AL (Pezzin, Kemper, and Reschovsky 1996; Goda, Golberstein, and Grabowski 2011; Grabowski, Stevenson, and Cornell 2012), NHs will have to adjust. Private-pay residents tend to be the most lucrative for NHs; therefore, many facilities prefer to admit privately financed residents when possible, often resulting in a documented difference in NH quality (Grabowski, Angelelli, and Mor 2004; Konetzka et al. 2004; Grabowski, Gruber, and Angelelli 2008; Cai et al. 2015). A reduction in the demand for private-pay NH residence may result in greater prevalence of Medicaid-financed residents in NHs, which has been often linked to lower quality of care (Grabowski, Angelelli, and Mor 2004; Konetzka et al. 2004; Grabowski, Gruber, and Angelelli 2008; Cai et al. 2015). Furthermore, the reduction in privately financed days of care may result in a decreased profitability of NHs and potential facility closures. Future work considering supply and demand characteristics is needed to ascertain if increases in the AL market directly affect the profitability of NHs, their behavior, and residents' outcomes.

\section{Limitations}

Our work is subject to several limitations. First, our RHF methodology for identifying privately financed $\mathrm{NH}$ utilization relies primarily on excluding residents and days that could be identified as covered by another payer (e.g., Medicare, Medicaid). It is therefore possible that our measure of private-pay utilization included other payers such as the U.S. Department of Veterans Affairs or private LTC insurance companies. In addition, we only account for large, licensed AL communities across the U.S., but there may be smaller or unlicensed facilities affecting the LTC market in ways we do not observe. We are also unable to account for the effects of other types of LTC such as home and community-based services or informal care provided by family members, which may play an important role in the shifting market for LTC services. As such, it is possible that AL supply is endogenous in our models. That is, some unobserved, time-varying market-level factor may be correlated with both AL supply and private-pay NH utilization. However, our analysis of Medicarefinanced $\mathrm{NH}$ utilization showed no significant relationship with changes in 
AL supply, which could have indicated such endogeneity with overall changes in market demand.

We are also limited by the AL data that are available. For example, we do not have data on ALs' occupancy rates. Data from the National Survey of Residential Care Facilities suggest 13 percent of facilities are at 95 percent occupancy or greater, 36 percent operate between 80 percent and 95 percent occupancy, 27 percent between 65 and 80 percent occupancy, and 23 percent are operating at $<65$ percent occupancy (Park-Lee et al. 2011). Therefore, we feel confident that our measure of AL bed supply is appropriate for capturing the capacity of the industry in providing an alternative to $\mathrm{NH}$ placement for private-pay residents. However, our results should be interpreted as the effects of a change in AL supply, not changes in AL utilization. In addition, we were only able to examine two points in time, the years for which we had a complete census of AL communities. Examining additional years could yield additional insights.

It is important to note that the observed relationship between AL supply and privately financed $\mathrm{NH}$ utilization is small in the context of overall reductions in the $\mathrm{NH}$ sector. In addition, very few markets experienced an increase of 1,000 AL beds, a value we selected to make our coefficients easier to interpret. We view this as indicative of AL supply playing a small but important role in NHs' shift in resident payer composition. Also, the county may be an imperfect measure of market area for LTC. As previously noted, we selected the county following the example of past work, but future efforts could consider different market-based measures (e.g., within 15 miles of the $\mathrm{NH}$ ). Finally, this work does not consider the drivers behind the expansion in AL supply, an area that is ripe for future research. Despite these limitations, our study is the first to use national data to suggest that increases in AL supply, controlling for temporal trends and market characteristics, are associated with reductions in the length of privately financed $\mathrm{NH}$ care.

\section{CONCLUSION}

In conclusion, our results suggest that as market-level supply of AL has increased over the past decade, a modest but statistically significant corresponding decrease in privately financed $\mathrm{NH}$ utilization has occurred across the United States. In markets where AL capacity has increased, we found a reduction in the proportion of $\mathrm{NH}$ days that were paid for privately by residents. As demand for AL continues to grow, it will be important to assess the spillover effects on other 
sectors of LTC, including the subsequent effect on NHs' operational structure, processes of care, and residents' outcomes.

\section{ACKNOWLEDGMENTS}

Joint Acknowledgments/Disclosure Statement: This work was supported by the National Institute on Aging (R21AG047303).

Disclosures: None.

Disclaimer: The views expressed in this article are those of the authors and do not necessarily reflect the position or policy of the National Institutes of Health, the Department of Veterans Affairs, or the United States government.

[Correction added on 20 August 2018, after first online publication: a disclaimer statement has been added.]

\section{REFERENCES}

AARP Public Policy Institute. 2017. DataExplorer - Assisted Living and Residential Care Facilities. Washington, DC: AARP Public Policy Institute.

Assisted Living Quality Coalition. 1998. Assisted Living Quality Initiative: Building a Structure that Promotes Quality. Washington, DC: Assisted Living Quality Coalition.

Banaszak-Holl, J., J. S. Zinn, and V. Mor. 1996. "The Impact of Market and Organizational Characteristics on Nursing Care Facility Service Innovation: A Resource Dependency Perspective." Health Services Research 31 (1): 97.

Bowblis, J. R. 2014. "Nursing Home Prices and Market Structure: The Effect of Assisted Living Industry Expansion.” Health Economics, Policy and Law 9 (1): 95-112.

Brown University School of Public Health. 2011. "Long-Term Care: Facts on Care in the US (LTCfocus)" [accessed on January 2017]. Available at http://ltcfocus.org/

Cai, S., S. C. Miller, D. L. Nelson, and D. B. Mukamel. 2015. "The Impact of Medicaid Payer Status on Hospitalizations in Nursing Homes." Medical Care 53 (7): 574.

Goda, G. S., E. Golberstein, and D. C. Grabowski. 2011. "Income and the Utilization of Long-Term Care Services: Evidence from the Social Security Benefit Notch.” Journal of Health Economics 30 (4): 719-29.

Grabowski, D. C. 2008. "The Market for Long-Term Care Services.” Inquiry: The Journal of Health Care Organization, Provision, and Financing 45 (1): 58-74.

Grabowski, D. C., and R. A. Hirth. 2003. "Competitive Spillovers across Non-Profit and For-Profit Nursing Homes." Journal of Health Economics 22 (1): 1-22.

Grabowski, D. C., J. J. Angelelli, and V. Mor. 2004. "Medicaid Payment and RiskAdjusted Nursing Home Quality Measures." Health Affairs 23 (5): 243-52. 
Grabowski, D. C., J. Gruber, and J. J. Angelelli. 2008. "Nursing Home Quality as a Common Good." The Review of Economics and Statistics 90 (4): 754-64.

Grabowski, D. C., D. G. Stevenson, and P. Y. Cornell. 2012. "Assisted Living Expansion and the Market for Nursing Home Care." Health Services Research 47 (6): 2296-315.

Hagen, S. A. 2013. Rising Demand for Long-Term Services and Supports for Elderly People. Washington, DC: Congressional Budget Office.

Harris-Kojetin, L., M. Sengupta, E. Park-Lee, and R. Valverde. 2013. "Long-Term Care Services in the United States: 2013 Overview." Vital \& Health Statistics Series 3, Analytical and Epidemiological Studies (37): 1-107.

Harris-Kojetin, L., M. Sengupta, E. Park-Lee, R. Valverde, C. Caffrey, V. Rome, and J. Lendon. 2016. "Long-Term Care Providers and Services Users in the United States: Data from the National Study of Long-Term Care Providers, 2013-2014.” Vital \& Health Statistics Series 3, Analytical and Epidemiological Studies 38: 1-118.

Hawes, C., C. D. Phillips, M. Rose, S. Holan, and M. Sherman. 2003. "A National Survey of Assisted Living Facilities." Gerontologist 43 (6): 875-82.

Intrator, O., J. Hiris, K. Berg, S. C. Miller, and V. Mor. 2011. "The Residential History File: Studying Nursing Home Residents' Long-Term Care Histories.” Health Services Research 46 (1 Pt 1): 120-37.

Kaye, H. S., C. Harrington, and M. P. LaPlante. 2010. "Long-Term Care: Who Gets it, Who Provides it, Who Pays, and How Much?” Health Affairs 29 (1): 11-21.

Khatutsky, G., C. Ormond, J. Wiener, A. M. Greene, R. Johnson, E. A. Jessup, E. Vreeland, M. Sengupta, C. Caffrey, and L. Harris Kojetin. 2016. Residential Care Communities and Their Residents in 2010: A National Portrait. DHHS Publication No. 2016-1041. Hyattsville, MD: National Center for Health Statistics.

Konetzka, R. T., D. Yi, E. C. Norton, and K. E. Kilpatrick. 2004. "Effects of Medicare Payment Changes on Nursing Home Staffing and Deficiencies." Health Services Research 39 (3): 463-88.

Park-Lee, E., C. Caffrey, M. Sengupta, A. J. Moss, E. Rosenoff, and L. D. Harris-Kojetin. 2011. "Residential Care Facilities: A Key Sector in the Spectrum of LongTerm Care Providers in the United States." NCHS Data Brief78: 1-8.

Pezzin, L. E., P. Kemper, and J. Reschovsky. 1996. "Does Publicly Provided Home Care Substitute for Family Care? Experimental Evidence with Endogenous Living Arrangements." Journal of Human Resources 31: 650-76.

Phillips, C. D., S. Holan, M. Sherman, W. Spector, and C. Hawes. 2005. "Medicare Expenditures for Residents in Assisted Living: Data from a National Study.” Health Services Research 40 (2): 373-88.

Stevenson, D. G., and D. C. Grabowski. 2010. "Sizing Up the Market for Assisted Living." Health Affairs 29 (1): 35-43.

Thomas, K. S., V. Mor, D. A. Tyler, and K. Hyer. 2013. "The Relationships Among Licensed Nurse Turnover, Retention, and Rehospitalization of Nursing Home Residents." Gerontologist 53 (2): 211-21.

Thomas, K. S., B. C. Silver, P. L. Gozalo, D. Dosa, D. C. Grabowski, V. Mor, and R. Makineni. 2017. "Constructing a Measure of Private-Pay Nursing Home Days." Medical Care 56 (5): e26-31. 
Thomas, K. S., D. Dosa, P. L. Gozalo, D. C. Grabowski, J. Nazareno, R. Makineni, and V. Mor. 2018. "A Methodology to Identify a Cohort of Medicare Beneficiaries Residing in Large Assisted Living Facilities Using Administrative Data.” Medical Care 56: e10-5.

Wiener, J. M., W. Anderson, G. Khatutsky, Y. Kaganova, and J. O'Keeffe. 2013. Medicaid Spend Down: New Estimates and Implications for Long-Term Services and Supports Financing Reform. Washington, DC: RTI International.

\section{SUPPORTING INFORMATION}

Additional supporting information may be found online in the Supporting Information section at the end of the article.

Appendix SA1: Author Matrix. 